\title{
Alcohol use and problems related to the Maxakali indigenous peoples' worldview: a cross-sectional census study
}

Roberto Carlos de Oliveira

Universidade Federal de Minas Gerais

Belinda Nicolau

McGill University

Rodrigo Venâncio da Silva

SES: Secretaria de Estado de Saude de Minas Gerais

Ana Valéria Machado Mendonça

Universidade de Brasília

Dilceu Silveira Tolentino Júnior ( $\nabla$ dilceujunior@bol.com.br)

Universidade Federal dos Vales do Jequitinhonha e Mucuri https://orcid.org/0000-0003-2435-7576

Andréia Maria Duarte Vargas

Universidade Federal de Minas Gerais

Efigênia Ferreira e Ferreira

Universidade Federal de Minas Gerais

\section{Research Article}

Keywords: South American Indians, alcoholic beverage, social problems, mixed methods reaearch

Posted Date: November 18th, 2021

DOI: https://doi.org/10.21203/rs.3.rs-999692/v1

License: (1) This work is licensed under a Creative Commons Attribution 4.0 International License. Read Full License 


\section{Abstract \\ Background}

The objectives of this study were to estimate the prevalence of Alcohol Use and Alcohol-Related Problems (AU \& ARP) among the Brazilian Maxakali indigenous people, and to examine how the prevalence varies according to sociodemographic characteristics and their associations with these characteristics.

\section{Methods}

A cross-sectional analytical population-based study was conducted with 1,036 Maxakali aged from nine years. A questionnaire was applied to 66 indigenous leaders who responded about alcohol consumption in 2016 and the negative consequences of this consumption among their friends in their villages. The association between consumption and consequences with the sociodemographic data of respondents was examined by applying the chi-square, Fisher's exact, and cluster analysis tests. Kappa values were calculated to assess the reproducibility of the questionnaire.

\section{Results}

The 12-month prevalence of alcohol use was $39.1 \%$. The usage rate for women (17.3\%) was 3.6 times lower than the usage rate for men. Male alcohol use rates increase from $8.1-64 \%$ in the age group from 09 to 14 to 15 to 19 years old. The highest proportions of alcohol use among mothers and fathers were found in extended families and associated with the negative consequences of those who use cachaça. On the other hand, nuclear families showed an association of protection against alcohol use in the age group of 9 to 14 years in females. Although alcohol use in females starts from 20 to 24 years of age, the rates of problems related to this use in women surpassed those of men during 25 to 45 years of age.

\section{Conclusions}

With the substantial agreement of reproducibility in the application of the questionnaire, we expect that the ease of application and the predictive power of this tool will allow the detection and monitoring of alcohol use and its consequences in the Maxakali people.

\section{Introduction}

Mortality statistics and epidemiology detail the disparity in consumption of alcohol, its damage to health, and its social and economic burden [1]. More than 200 codes of diseases and health hazards included in the tenth revision of the International Classification of Diseases (ICD-10) list harmful alcohol consumption as a component cause. These diseases and conditions would not exist in the absence of 
harmful alcohol consumption. Of these, more than 30 included alcohol consumption in the definition of the disease, the necessary cause being, for example, alcoholic liver disease [2].

From 2000 to 2017, 288 deaths were reported among the Maxakali indigenous people, and $25.3 \%$ of these deaths occurred among people aged 20 years and over. The two main causes of death in this age group are represented by the groups of External Causes (21 individuals: $28.8 \%$ ) and by injuries, poisoning, and some other consequences, with 11 deaths (15.1\%) [3]. In the age group from 20 to 49 years, 23 deaths $(72 \%)$ and $28 \%$ over 49 years were registered. Regarding gender, $25(78 \%)$ occurred among men. The underlying causes reported were $26(81.3 \%)$ due to aggressions, injuries, and trauma and $3(9.4 \%)$ due to alcohol intoxication.

In addition to these 32 deaths where harmful alcohol consumption can be linked as a component cause, in the group of necessary causes, there are four deaths. Two (02) deaths from liver cirrhosis; one (01) due to alcoholic liver disease and one (01) death due to addiction syndrome [3]. These 36 deaths represent $49.3 \%$ of deaths in Maxakali aged 20 years and over.

Results of the National Survey on Patterns of Alcohol Consumption among Brazilian Indigenous Peoples [4] showed that $38.4 \%$ (559) used alcohol and 25.6\% (372) drank but stopped. Among the 931, the dependency rate was $22.9 \%$, higher than that found in the Brazilian population (12.3\%) for 2007. Dependence among women (11.8\%) is twice as much as the population of Brazilian women (6.9\%), while for men $(28.7 \%)$, compared to $19.5 \%$ of the general population. Also, with dependency, the age group with the highest rate was for the 18 to 24 age group with $29.3 \%$, while in the general population it was $19.2 \%$ for the same age group [4]. Regarding the pattern of alcohol use, $44.1 \%$ had a diagnosis of harmful use, which was higher among indigenous women (44.9\%), compared to $41.1 \%$ of men [5].

For the Maxakali, with the replacement of the traditional fermented beverage by distilled (cachaça), some cultural practices were shaped by interethnic contact and are related to negative issues for drinkers and people in their social environments (families, villages, and communities), according to Oliveira et al., $2018 ; 2019[6,7]$.

Given the harmful health consequences and the social and economic burdens for the drinker and people related to him by the harmful use of Kaxmuk (cachaça) among the Maxakali, it's necessary to conduct new studies to examine the use patterns of alcohol use and alcohol-related problems (AU \& ARP) among and within the Maxakali population [7, 8]. With the growing increase in the indigenous population in Brazil occurred in recent decades, alcohol use and related problems need to be better understood, particularly in the AU \& ARP with the Maxakali. Assumptions based on samples from studies in the general or indigenous population about the antecedents of alcohol use and its harmful consequences in Brazil cannot be applied to the Maxakali.

This gap asks us: what is the prevalence of alcohol use and harmful consequences related to harmful use in the Maxakali population from nine years of age onwards? How do alcohol use and consequences related to the sociodemographic characteristics of this population? The objective is to reflect on the 
associations of AU \& ARP measures in the Maxakali worldview, considering gender, age group, family structure, and parental alcohol use.

The objectives of the present study were: (i) to estimate the proportion of AU \& ARP and to examine how the prevalence varies according to sociodemographic characteristics; (ii) to examine AU associations and their consequences to these characteristics.

\section{Methods}

\section{Study design and sample}

This was an analytical cross-sectional study with a census sampling. The sample was designed according to qualitative research findings on AU initiation among the Maxakali [6] including all the 1,036 Maxakali older than eight years of age residing in the Água Boa and Pradinho communities, located in the municipalities of Santa Helena de Minas and Bertópolis, state of Minas Gerais, Brazil (Fig. 1).

\section{Procedures}

The informed consent form 1 was signed in duplicate by each leader and researcher, representing an ethical agreement to keep their relatives' alcohol consumption a secret. The researchers assumed that they will not allow another Maxakali to know the names of the drinkers and their villages; but they will share the results in numbers by villages, with other names, and communities about who drinks and who causes problems when they use alcohol.

This research was approved by the Research Ethics Committee of the Federal University of Minas Gerais and by the National Research Ethics Committee, CAAE-1.438.160.

During the quantitative data collection, the collectivist characteristic of the Maxakali culture was explored. According to ethnographic studies, their societies are governed by the notion of person, in which there is no individual / collective dichotomy [9-11]. Their collective responsibilities for the actions of others regulate individual behavior. This collective responsibility models collective behaviors in society $[9,12]$. Rather than developing a questionnaire to be applied individually and exploring the individual's spontaneous representation of symptoms linked to AU \& ARP [12,13], we explored the collectivist culture of 66 intentionally selected Maxakali leadership [9-11]. These could respond to the AU and ARP experiences of their $\geq 9$-year-old relatives from their 19 villages in the last year [14]. During Qualitative Phase 1 of the Mixed Methods Research [6,7], researching and drawing with Maxakali allowed the researchers to describe and illustrate the experience of the interviewees in their life stories regarding AU and ARP in their villages [7]. 
The research findings were organized in three dimensions: (1) alcohol use pattern (initiation, frequency, quantity); (2) contexts (access, where, how, when, and who), and (3) the ARP (family and village) [6,7]. Dimensions were pooled and interrelated to the drawings in a PowerPoint Presentation to be shared publicly with each community. It was planned, before the interview, to contextualize and describe in Portuguese and Maxakali languages, the meanings of these dimensions about two issues. The first question is about the AU between relatives, a question that opens a less invasive dialogue on a delicate topic: alcohol consumption [14]. It has to be noted that, every one regarding from the primary socialization sources [15], as family, village, and house of chants in this study, is a relative or a friend from the allied family in Maxakali world view.

The other is about ARP on the consumption of relatives [7]. These questions are considered to be effective predictors of both current and future adverse alcohol outcomes $[10,16,17]$. A nominal census of 1,036 Maxakali $\geq 9$ years of age from the two communities was obtained in spreadsheets in the .xls file format. Each individual is identified by the system with nine variables. We worked on these worksheets adding the AU and ARP variables, which were printed and used as questionnaires.

\section{Dependent variables - Alcohol Use (AU) \& Alcohol-Related Problems (ARP)}

For AU and ARP, the 66 leaders were asked whether, if a relative from family " $A$ ", " $B$ ", and " $C$ " from the village $A B 01$, for example, had drunk cachaça in the past year. Each relative $\geq 9$ years of age was coded (1) did not drink (2) drank. Among those who drank cachaça, they also identified what kind of behavior they experienced, the options for responses were:

(a) Personal consequences: (1) when a relative drinks, he/she does not cause social problems [7]; (2) when a relative drinks, is a problem for himself;

(b) Violent behavior: "drink and become a jaguar": when a relative drinks, he or she may experience a kind of trance. he or she feels transmuted into a jaguar and can fight or kill people or animals. Then he or she returns to normal and does not remember exactly what happened [7]: (1) when the relative drinks, does not have violent behavior; (2) when the relative drinks, he or she becomes a jaguar;

(c) Family neglect: "lack of parental care due to excessive spending on alcohol or negotiation of the fair and household items by cachaça" [7]: (1) when the relative leaves for the city, drinks, but keeps part of the money for family expenses; (2) a relative goes out to the city, drinks and does not buy the fair or negotiates the fair and the domestic utensils for cachaça;

(d) Child neglect: "mother who, when she drinks, forgets to care for her children" [7]: (1) a relative who is mother and drinks but cares for her children; (2) a relative who is mother and drinks, but does not care for her children when she is drunk. 
To obtain a score of relatives who consume cachaça and need more care regarding their behaviors, the sum of ARP for each relative was taken into account. A coding was created from the leaders' perspective with three levels: For social drinkers, relatives who drank and did not cause social problems, Score 1. Relatives with one consequence received Score 2. Score 3 was given to relatives who presented two or three consequences.

\section{Independent variables: sociodemographic characteristics}

Subjects were coded from 1 to 1036; the gender (1) for women and (2) for men. Age in years and grouped in age groups: $9-14,15-19,20-44,25-45$ and 46 years and over.

The relation of kinship was obtained from the forms of the family: (1) married mother; (2) married father; (3) widowed mother, separated or single; (4) widowed father, separated or single parent; (5) grandfather or grandmother; or (6) child; stepchild, nephew/niece, grandson/granddaughter [3].

In these forms $[3,18]$, the family structure is classified according to the main characteristic of the composition of the residence: (1) Mother-Father family: presence of father and mother with biological child, being able to still have stepdaughters, nephews, etc. (2) Single-Parent family: presence of only one parent, widowed, divorced or single with children, cousins, relatives without grandparents; (3) Extended family: presence of more than one nuclear family or Single-Parent family with or without grandparents; being able to have stepdaughters, nephews, etc [3].

From the forms of the family [3], the per capita monthly family income of the 224 households was obtained. The median was calculated and a dichotomous measure was constructed with the median income: (1) gains $\geq R \$ 65.20 ;$ gains $\leq$ to $R \$ 65.1918$.

The consumption of alcohol by the mother and/or the father was identified in the SPSS program by crossing the relation of the variables of kinship with "Use of Alcohol". For the identification of alcohol consumption by parents in an extended family, the mothers and/or the older parents of these residences were chosen to represent this condition, which was extrapolated to all members of that household.

This variable had some 140 missing observations because many interviewees lived in homes where they did not have a father or a mother or both responsible for researching alcohol consumption by parents. These observations were grouped into the non-response category.

\section{Measuring the variability and reproducibility of answers to the two questions: Test-retest and ethical aspects}


At another time, a test-retest was performed to assess the reproducibility of the questionnaire [19]. The same data collection methodology was replicated with the same key informants. The same ethical aspects adopted, with the use of new informed consents were adopted. The interval for reapplication of the tracking questionnaire for the two communities was 11 to 14 days, a time considered adequate for this type of activity [20]

\section{Data analysis}

First, we describe the proportion of respondents' relatives who consumed cachaça, and among them the ARP types of their relatives. Second, we examined the association between AU \& ARP and sociodemographic data of relatives. Bivariate associations were examined using Pearson's $\chi^{2}$ [21]. We expected that some of the group differences revealed in consumption and behavior experienced, at least in part, would reflect different levels of the other independent variables. For example, the different levels of ARP between both genders may reflect, in part, that consumption habits vary between the ages of men and women.

The cluster analysis technique based on the two steps cluster method was used to determine the profiles of the Maxakali for sociodemographic variables of interest [22,23]. The groups generated by this analysis have the characteristic of internal homogeneity in each group and significant differences between the groups generated. The association/relationship between two categorical variables were performed using the chi-square test [21]. Fisher's exact test is similar to the chi-square test and was applied when the number of expected cases below 5 occurred $[21,24]$. All the results were presented in percentage values in order to describe the results of the studied variables [25]. These were considered significant for a probability of significance of less than $5 \%(p<0.05)$, with at least $95 \%$ confidence in the conclusions presented.

Third, we describe the AU and the authors of the ARP with sociodemographic variables of the contexts where the ARP was developed. The analysis were conducted in SPSS version 22. Finally, we evaluated the reproducibility of the questionnaire, calculating the Kappa concordance index [19].

\section{Results}

\section{Population and sample}

The communities of Água Boa and Pradinho are made up of 224 households, 326 families with a population of 1,636 people (Fig. 2); together they represented $78.2 \%$ of the Maxakali indigenous population [3]. 
The sample consisted of 1,036 people, whose ages ranged from 9 to 97 years old, with a mean of 25.4 years and a standard deviation of 15.3. Differences between gender and age were not significant (510 men and 526 women), with 636 (61\%) between nine and 25 years old and 400 (39\%) over 26 years old; living with 250 mothers, 209 fathers, and 91 grandparents in 119 (53.1\%) nuclear families, 21 (9.4\%) single-parent families and 84 (37.5\%) extended families.

\section{Alcohol use (AU)}

The prevalence of alcohol use is frequent. In Maxakali, the 12-month prevalence of alcohol use was $39.1 \%$. The usage rate for women $(17.3 \%)$ was 3.6 times lower than the usage rate for men $(61.6 \%)$.

The 12-month prevalence of alcohol use was $56 \%$ in the $20-24$ year age group, increasing to $77.9 \%$ in those over 45 years of age. The rates of use among young adults ( 20 to 24 years old) are higher among men $(95.6 \%)$ than among women $(8.8 \%)$.

The 12-month prevalence showed great variation between genders in adolescence. In boys, the use began in the age group of 9 to 14 years (6.7\%), increasing to $62.9 \%$ in the age group 15 to 19 . At 16 years of age, $50 \%$ of adolescents drink, reaching $68.8 \%$ at 17 .

Among women, the onset was later at 20 to 24 years of age (8.8\%), increasing to $25.3 \%$ at 25 to 45 years of age, reaching $74.2 \%$ above 45 years of age.

Regarding communities, the prevalence of 12 months of alcohol use in Pradinho was higher $(41.7 \%)$ than in Água Boa (36.2\%). The use rate for women was lower in Água Boa (14.3\%) while in Pradinho it was $20.1 \%$. Regarding the rates for men, in Água Boa this was four times higher than among women and three times higher in Pradinho.

Considering the lowest and highest rates in the villages, the prevalence of 12 months of alcohol use in Água Boa, the village with the lowest rate was in AB13 (25.9\%) for the highest (58.8\%) in village AB09. In Pradinho, this variation was $30.7 \%$ (PR05) to $47.7 \%$ (PR02).

Village AB03 in Água Boa stands out for having a higher rate of alcohol use among men, $87 \%$, while no women drink. In Pradinho, village PR05 had the lowest rate for women (6.3\%), and village PR01 with the highest rate for men (76.9\%). The villages with the highest rates among women were found in villages $A B 05$ and $A B 08$, both with $33.3 \%$, in Pradinho village PR02 with $29.6 \%$.

\section{Social problems related to alcohol use}

Among the 405 (39.1\%) who use cachaça, 246 (60.7\%) identified harmful use of consumption that causes damage to health and social problems for the drinker and the people around him and the 
community, generally. In women and men, the ARP rates were $61.8 \%$ and $63.4 \%$, respectively.

The initiation of $\mathrm{AU}$ among women occurred between the ages of 20 to 24 years, however, the rates of ARP in the last 12 months reach $40 \%$ of women of these ages. From age 25 to 45 , rates for women exceed the ARP rates for men of this age ( $82.5 \%$ vs. $66.4 \%)$.

Pradinho was the community that presented the highest rates of ARP $63 \%$ when compared to Água Boa (57.7\%). In Água Boa, the prevalence rates of ARP in women (66.7\%) were higher than among men (55.4\%).

For the ARP rates in the clusters, women had higher rates than men, 10 of the 13 villages in Água Boa, and 2 in Pradinho. It is noteworthy that in six villages in Água Boa, all women who use alcohol have ARP. In Pradinho, only the PR04 village, $100 \%$ of the women have ARP.

Concerning violent behavior and the loss of family bond of the individual who drinks cachaça, the rates showed similar behavior between genders. Gender differences were identified between communities; while in Pradinho the highest rates were found for $61.1 \%$ men, in Água Boa women had the highest rates (61\%).

For the negligence linked to parents who go to the city to sell their agricultural surpluses or receive their payments to buy the food market for their families, 31 friends were identified, 30 men and one woman. Regarding mothers who do not take care of their children when they drink, they recognized that 15 female friends showed this behavior when using cachaça, 14 friends who drink cause problems for him, $86 \%$ of them, male.

\section{Participation of determining variables of AU \& ARP and sociodemographic variables}

Considering the variables of interest for AU \& ARP, there was an indication of the existence of four and three clusters analyzing the measures of the measures considered for this selection (Ratio of AIC change and Ratio of Distances Measure), respectively. There was a total of 896 individuals who participated in this study. The distribution forms in the clusters for AU and ARP are shown in Tables 1 and $\mathbf{2}$, respectively.

The variables AU and ARP were the two Determining Variables (DV) in the construction of the clusters, and there were significant differences between their respective clusters. The results of the comparative analyzes between the clusters about the variables of interest regarding the AU \& ARP are presented in

\section{Tables 3 , and 4, respectively.}

It can be observed that, in terms of gender and monthly per capita family income, no significant differences were observed between the DV-ARP clusters. While for the DV-AU, the family income was also not significant. 
In the study of the association between the DV-AU clusters and the variables related to the community, it was observed that the Pradinho community has a higher percentage of individuals belonging to the 2nd cluster and the Água Boa community has a higher percentage of individuals belonging to the 3rd cluster. For DV-ARP, it was observed that the two communities showed similar behavior.

Each of the villages had its behavior about the clusters and the DV-AU, as an example, village AB09 with $66.7 \%$ of individuals belonging to the 2 nd cluster and village $A B 11$ with $58.8 \%$ of individuals belonging to the 3rd conglomerate. For DV-ARP, each of the villages had its behavior about the clusters, as an example, village $A B 05$ with $100 \%$ of individuals belonging to the 2 nd cluster and village $A B 07$ with $72.7 \%$ of individuals belonging to the 3rd conglomerate.

\section{Reproducibility}

In assessing the reproducibility of the questionnaire [19], the Kappa values for consumption was 0.90 , considered almost perfect. For problem drinking the coefficient was 0.74 considering a substantial agreement [26].

\section{Discussion}

\section{The historical context of why Maxakali uses cachaça}

Alcohol is a psychoactive substance with addictive properties that has been widely used in many cultures for centuries. The use of alcoholic beverages has been an integral part of many symbols and meanings of Brazilian indigenous peoples [27-30]. Before the modern era, fermented alcoholic beverages, such as corn, cassava, sweet potatoes, head of morotó, coconut palms, trampled in coconut water, among others, were known in many indigenous communities, or Brazilian mining villages [6,8,27].

In indigenous communities, including the Maxakali peoples, where alcohol was traditionally consumed, the production of their alcoholic and non-alcoholic fermented beverages generally took place on a small scale, as a domestic or collective activity, generally, the responsibility of the female gender [27] who used their fermentation techniques. This is when and where surpluses from their hunting, gathering, and small plantations were seasonally available [29]. Therefore, alcohol consumption was often an occasional and community activity, associated with the ceremonial use of rituals or community festivals [27,31].

Overlapping, and often replacing the traditional patterns of production and consumption mentioned above [6,32,33], are the production and consumption patterns of distilled beverages that developed in European empires and during the industrialization of the early modern era [1,27]. In 2018, there is the first report of the use of Kaxmuk (cachaça) among the Maxakali [8], a drink with potentially higher alcohol content than their traditional drinks described [6]. 
Today, cachaça has made it available, and transportation has improved. It became a market product that is available in all seasons of the year and at any time during the week [8-11]. This increase in the supply and availability of spirits, often involved in the frontier of interethnic relations, and the resignification of traditional use [28], contributed to the establishment of harmful use of alcohol for the Maxakali [6-8,3234].

The historical and cultural analysis presented here has practical implications for overcoming the problems of harmful alcohol use by the Maxakali [30]. Since any attempt to develop a viable intervention program needs to consider the historical sources of Kaxmuk consumption problems in addition to risk factors in contemporary life $[12,35,36]$. Knowledge of the formation of the Tikmũ'ũn $[11,10,8,9]$ and the intense social and economic forces that helped to shape the first native experiences with Kaxmuk (Rubinger, 1980), help to provide a more balanced perspective on the roots of contemporary consumption pattern problems [1].

\section{Who: gender, age, and life stages of cachaça consumption}

Among the Maxakali indigenous people $\geq 9$ years of age, the prevalence of 12 months of alcohol use was $39.1 \%$. Although surveyed among different age groups, the prevalence of alcohol consumption in Maxakali was higher than that found by the Kaingang of Paraná $(29.9 \%)$ and very close to the rate found in the first survey of alcohol use among Brazilian indigenous peoples of $38.4 \%$ [3]. In contrast, $60.9 \%$ of Maxakali are abstainers, practically double the rate of $30.7 \%$ for the Brazilian population [1].

The usage rate for women (17.3\%) was 3.6 times lower than the usage rate for men (61.6\%) and lower than the $24.4 \%$ rate found for the indigenous female population in Brazil $\geq 18$ years old (Brasil, 2007).

In addition to gender, age is also an important factor in the initiation of alcohol consumption, which has implications for the establishment of interventions for prevention and control [31,36]. In Maxakali men, use began in the age group 9 to 14 years (5.7\%), increasing to $62.9 \%$ in adolescence. On the other hand, among women, the onset occurred later at 20 to 24 years of age (8.8\%), increasing to $25.3 \%$ at 25 to 45 years of age, reaching $74.2 \%$ above 45 years of age.

In some indigenous groups, such as the Teréna, Gavião, Xavante, Karajá, Tikuna, Kayapó, Kaiwá, Xakriabá, Makuxi, the consumption of distilled beverages begins between 10 and 12 years of age, and sometimes even at seven years of age. This pattern is also observed among the Maxakali. According to studies, the fact that they start drinking at this age seems to mark male initiation ceremonies [29,31].

Although there are no studies on alcohol use in Maxakali male initiation ceremonies (Oliveira et al., 2018), which occurs around 5 to 9 years of age [11] or up to 12 years of age (Popovich, 1980). For boys, it involves receiving a song from one of their parents or relatives (grandparents, older brother, or uncle). This 
song they should learn and know how to sing without hesitation during the ceremony. This ceremonial is not related to the acquisition of physical maturity, but to your ability to assume religious responsibilities [10].

As highlighted in the findings of qualitative research (Oliveira et al., 2018; 2019), it is suggested to link the role of alcohol consumption with the roles of parents and grandparents in the transmission of this knowledge to their children: "my father, while drinking, taught me the religion chant" and even to their grandchildren: "I got married and my wife had a baby. We were under postpartum care and my father came to visit us. He gave me Kaxmuk to teach me some songs of the Bat and the Hawk rituals'. In these cases, what leads the person to drink is is a sensation experienced by the drinker, whereby he or she demonstrates knowledge: 'My father while drinking, taught me the religious song and told me the story of our [6].

\section{The Maxakali pattern of drinking (quantity)}

The teenager, after starting to drink Kaxmuk, takes a glass and then another glass, with 10 minutes, another half a glass later; he gets dizzy with two and a half glasses. Then it falls, it can't take it anymore $[32,33]$. (...) In my village, my brother drinks a lot! When he wants to drink, he drinks Monday, Tuesday, Wednesday, Thursday, Friday; on Saturday, he finishes and cures his hangover. Then he goes for a month without drinking. Today, I drink a full glass, and right afterward I drink it again. My brother-in-law drinks three glasses, and then he loses control of his head, up to a month; everyone is still [7].

Considering the definition of abusive consumption of 5 doses $(225 \mathrm{~mL}$ or $70 \mathrm{~g}$ of pure alcohol) of alcoholic beverage on one occasion for men and $4(180 \mathrm{~mL}$ or $56 \mathrm{~g})$ doses for women [2], it is observed that the consumption of 2 and a half glasses of cachaça $(450 \mathrm{ml}$ or $144 \mathrm{~g}$ of pure alcohol) among teenagers Maxakali is double the five doses defined for heavy consumption for men. When you drink three glasses, you consume seven doses more than the five, considered as the cutoff point for abusive consumption.

Compared to adults, children and adolescents tend to have higher blood alcohol concentrations after drinking similar amounts of alcohol [14]. Extrapolating from what is known about alcohol metabolism in adults, excessive alcohol consumption for young people should be defined as follows: 3 doses for ages 9$13 ; 4$ doses ( 14 to 15 years) and 5 for $\geq 16$ years of age) [14,34]. This implies that when Maxakali teenagers drink 2 and a half glasses of cachaça, they are taking 7, 6, 5 doses in addition to the doses defined for abusive consumption for their respective age groups.

These results represent a warning condition already highlighted in studies on the trajectories of alcohol consumption among American Indian adolescents. These studies indicate that the younger the age of onset of consumption, the greater the chance of developing harmful use symptoms and alcohol use disorders in adulthood in these adolescents [12, 35-37]. 


\section{Sociodemographic and cultural characteristics of cachaça consumption and harmful consequences to health}

When a Maxakali consumes cachaça and crosses the boundaries (of thinking, acting, imagining, and judging) of his people's culture, both the person who drinks and the others in his sociocultural environment can be affected by harmful consequences of this use $[6,8,9,38]$. In the world of life, the consequences related to the harmful use of cachaça were presented in the form of accidents, marital disharmonies, negligence [6], in addition to violent behavior, illnesses, and deaths [5,6], in addition to the individual who drinks, families and villages are also affected by these consequences [6].

About families, there are cultural differences in their definition and, therefore, in the role of the family in primary socialization [15]. For example, in the Gê tribes, the elders have specific roles and are generally highly regarded. The grandparents and fathers of extended families exert great influence through their opinions, as do the Maxakali [10]. Therefore, the main source of socialization responsible for the task of raising children is more likely to involve a relative other than the biological parents [15].

However, these differences do not violate the general principle that, in virtually all cultures, the family is one of the main sources of primary socialization, and the effect of the family on socialization depends on the bond and the transmission of norms of behavior patterns between its members [15].

The results of the present study show that in Maxakali extended families, $95.2 \%$ of the fathers drink and it was in these families that the highest proportion (80.4\%) of use of Kaxmuk by mothers was observed. Thus, while it is possible that grandparents can serve as vital and supportive cultural role models, it is also possible that their previous life experiences similarly encourage substance use among younger generations $[15,39]$.

This is a potentially important condition, given the central role that grandfathers and grandmothers, father and mother of an extended family play in many indigenous families [37,39]. For example, for the Maxakali, the mother is always close to her baby as long as the baby is not weaned, when other older members of the family or the younger members of the father's family begin to provide the help and protection that the child received from the biological mother. The real discipline, by the way very severe, is given by these relatives [10]. This holistic and combined family effort in early childhood education is a cultural force that can play a key role in the social ecology of substance use [37].

The results of this study corroborate the findings of a qualitative research with the Maxakali, where the role of alcohol consumption is linked with the roles of parents and grandparents in the transmission of cultural norms: "My wife and I were on guard. My father came to visit us and gave me cachaça to teach me singing (rituals)" [6]. That is, while the father or grandfather or both drink to sing religious songs, they can, in addition to transmitting social norms through learning the songs of religion and stories of 
ancestors, also determine patterns of AU behavior, while culture is transmitted through each generation [15].

In contrast, where $100 \%$ of individuals aged 9 to 14 years do not drink, come from the Maxakali nuclear families. The results showed a protective association with the use of alcohol; in this family structure, the lowest proportions of alcohol use among parents were observed, reaching $97.9 \%$ of mothers and $21.4 \%$ of fathers who do not drink. Differences in alcohol consumption are also related to the parental transmission of substance use behavior norms. The high abstinence rates of mothers from nuclear families corroborate the findings of other studies that associate the low prevalence of alcohol use among women with family organization and the exercise of roles assigned to indigenous women [40,41]. Within the domain of family roles, maternity emerges as a particular protective factor for alcohol consumption $[6,12]$.

It is noteworthy that, while the proportion of teenagers who drink have harmful consequences related to the consumption of cachaça is $4.5 \%$ in the ARP2 Conglomerate, where Nuclear Families are predominant, in the ARP3 Conglomerate, where there is $97.9 \%$ of Extended Families this proportion increases more than five times for adolescents, young adults and elderly in these families. It is also observed that this conglomerate was the one with the highest proportions of alcohol use by the mother $(71.5 \%)$ and by the fathers $(98.8 \%)$ of these extended families.

In the ARP1 cluster, the highest proportion of negative consequences related to the use of cachaça was identified (38.4\%). In this conglomerate, consisting exclusively of individuals aged 25 to 45 years, the results of this study show association of harmful use of cachaça with damage to health and social problems in this age group, regardless of gender and family structure.

Results of research that analyzed the relationships of family structure with alcohol use highlight that living in families with separated parents is a risk factor for the development of early use in adolescence and disorders related to alcohol use in adulthood [35,37,39]. In the present study, no relationship was observed between single-parent families and other types of families regarding the use of cachaça and its related consequences.

Alcohol is typically a consumer good for the Maxakali $[9,38]$, which means that drinking normally uses resources that would otherwise be available for other purposes [6]. Where earnings are low, excessive alcohol consumption can further impoverish the drinker, the drinker's family, or the entire community, thus increasing health damage and social problems [1]. Regarding monthly per capita family income, research results show that children living in low-income families are more likely to report substance use, including alcohol [1]. In the present study, family income did not show significant associations with either AU or ARP among the Maxakali. Corroborating the evidence that socioeconomic status permeates the effect of family structure on substance abuse, it has been weak or inconsistent $[18,39]$ and is not responsible for the increased problems of alcohol use. 


\section{Limitations}

One of the strengths of this study is that it is pioneering and the only one to include the entire Maxakali population over eight years of age. However, there are several limitations. The results of this study with the Maxakali cannot be extrapolated to other Brazilian indigenous peoples. The cross-sectional design of the study also prevents causal interpretations of the observed associations. We do not know if cachaça consumption is influenced by the availability of the alcohol source or if the alcohol source influences the drinking behavior. For example, as Maxakali does not produce cachaça, it is not clear whether young people who obtain alcohol from a certain source drink more alcohol or whether consumption behaviors are related to the specific sources where alcohol is sold.

It may be that in interethnic contact relationships young people who drink frequently are more dependent on certain sources or are more likely to access alcohol through various sources in their contact relationships, compared to young people who drink infrequently. On the other hand, it may be that larger amounts of alcohol are obtained from certain sources, which leads to heavier consumption. Longitudinal surveys are needed to better determine the directionality of these relationships.

Given the collectivist orientation of the Maxakali culture, understanding the influence of the roles of other members of the extended family, as well as the transmission of norms of behavior patterns related to the etiquette of the use of cachaça are demands of this agenda. This research may contribute to the expansion of studies on this theme to build knowledge of how the Maxakali will behave in front of an AU \& ARP prevention and control program.

\section{Conclusions}

Many of the results presented here replicate those of other studies [31, 36, 42]. First, male alcohol use rates increase from $8.1-64 \%$ of the age group from 09 to 14 to 15 to 19 years old. Second, early alcohol use among young people was associated with the onset of harmful health consequences and social and economic problems in adults.

Third, at least at younger ages, in females, the high abstinence rates of mothers corroborate the findings of other studies that associate the low prevalence of alcohol use among women with family organization and the exercise of roles assigned to indigenous women.

Fourth, the highest proportions of alcohol use among mothers and fathers were found in extended families and associated with the negative consequences of those who use cachaça. On the other hand, nuclear families showed an association of protection against alcohol use in the age group of 9 to 14 years in females. However, the highest proportions of problems related to alcohol use were in adults aged 25 to 45 years, without distinction by gender or family structure. 
Fifth, although alcohol use in females starts at 20 to 24 years of age, the rates of problems related to this use in women surpassed those in men during 25 to 45 years of age.

Although these results are not new, they establish that in males, Maxakali boys and young people constitute a unique group concerning perceived parental norms and alcohol-related problems in the 15-19 year age group. From a prevention standpoint, programs that have been found effective in reducing alcohol consumption in other populations in this age group may not be effective for the Maxakali.

The critical period from late childhood to early adolescence for intervention efforts in these communities is evident. Interventions must be early and gender sensitive. Should start with boys before age 9 and for women before age 20 to delay the onset of use and the harmful consequences associated with harmful use of alcohol. It is also noted that more intensive prevention efforts are indicated for young people who had their father and mother diagnosed with alcohol use.

The usual practice is to transfer responsibility for education and prevention of alcohol use to schools as children grow. Including Maxakali families in prevention aimed at late-onset alcohol use and reducing consumption levels among boys and women can reduce morbidity and mortality among Maxakali $\geq$ to 20 years of age. This family approach must bring together strong cultural values of care and sociability for at-risk youth and women.

Finally, effective and sustainable interventions must be grounded in the two Maxakali communities, embodying their worldviews on effective prevention. Participatory research must be implemented, bringing together the scientific experience of researchers and the cultural experience of community members.

With the almost perfect and substantial agreement of reproducibility in the application of the questionnaire for AU \& ARP, we hope that the brevity, ease of use, and predictive power of this new tool, built from this study, will allow the detection and monitoring of the AU \& ARP and avoid harm as soon as possible to children under the age of nine and young Maxakali women.

\section{Abbreviations}

$A B$

Água Boa

ARP

Alchool-related problem

AU

alcohol use

g

gram

ICD

International Classification of Diseases 
$\mathrm{mL}$

milliliter

PR

Pradinho

PRAU

Problems Related to Alcohol Use.

\section{Declarations}

\section{Acknowledgments}

We would like to thank all subjects participating in the research because without their contribution this research would not be possible.

\section{Authors' contributions}

All authors contributed significantly to the conceptualization of this manuscript.

\section{Ethics approval and consent to participate}

This research was approved by the Research Ethics Committee of the Federal University of Minas Gerais and by the National Research Ethics Committee, CAAE-1.438.160.

\section{Consent for publication}

The research subjects signed the consent for the publication of their results in a way that did not identify the entity of the participants.

\section{Availability of data and materials}

The datasets used and/or analysed during the current study are available from the corresponding author on reasonable request.

\section{Competing interests}

The authors declare that they have no competing interests.

\section{Funding}

Not applicable.

\section{References}

1. World Health Organization. Global status report on alcohol and health - ed. Geeneva. 2014. 
2. DSM-V (Diagnostic and Statistical Manual of Mental Disorders). 5th Edition: DSM-5. American Psychiatric Association's classification and diagnostic tool. 991p. 2013.

3. Brasil. Ministério da Saúde Sistema de Informação da Atenção à Saúde Indígena (SIASI). Distrito Sanitário Especial Indígena de Minas Gerais e Espírito Santo/SESAI/MS. 2017.

4. Brasil. Secretaria Nacional Antidrogas. I Levantamento Nacional sobre Padrões de Consumo de Álcool e outras drogas entre populações indígenas. Brasília: Secretaria Nacional Antidrogas; 2009.

5. Brasil. Ministério da Saúde. Plano de Ação de Saúde Mental Maxakali. Povo Indígena Maxakali. Distrito Sanitário Especial Indígena de Minas Gerais e Espírito Santo - DSEI-MGES/SESAI/MS; 2016. $157 p$.

6. Oliveira RC. Uso de álcool e problemas relacionados no povo indígena Maxakali/MG: a visão de mundo maxakali. [tese]. Belo Horizonte: Universidade Federal de Minas Gerais. 2018.

7. Oliveira RC, Nicolau BF, Levine A, Mendonça AVM, Videira V, Vargas AMD, Ferreira EFE. "When a Tihik drinks kaxmuk he neither has a father, nor a mother, or a brother": perceptions of Maxakali on the effects of sugarcane liquor consumption. Cien Saude Colet. 2019;24(8):2883-94.

8. Pena JL. Os índios Maxakali: a propósito do consumo de bebidas de alto teor alcoólico. Revista de Estudos e Pesquisas FUNAI. 2005;2(2):99-121.

9. Ribeiro RB. Guerra e paz entre os Maxakali: devir histórico e violência como substrato da pertença [tese]. São Paulo: Pontifícia Universidade Católica de São Paulo; 2008.

10. Popovich FB. A organização social dos Maxakali [tese]. Arlington: Universidade do Texas; 1980.

11. Álvares MM. Yãmiy, os espíritos do canto: a construção da pessoa na sociedade Maxakali [tese]. Campinas: UNICAMP; 1992.

12. Swain RC, Beauvais F, Walker RD, Silk-Walker P. The effects of parental diagnosis and changing family norms on alcohol use and related problems among urban American Indian adolescents. Am J Addict. 2011;20(3):212-9.

13. Barbor TF, De La Fuente JR, Saunders J, Grant M. The Alcohol Use Disorders Identifications Test: guidelines for use in primary health care. Geneva: World Health Organization; 1989.

14. Johnston LD, O'Malley PM, Bachman JG, Schulenberg JE. Monitoring the future national survey results on adolescent drug use: Overview of key findings. Ann Arbor: Institute for Social Research. The University of Michigan; 2010.

15. Oetting ER, Donnermeyer JF. Primary socialization theory: the etiology of drug use and deviance. J subst use misuse. 1998;33(4):995-1026.

16. Spillane NS, Smith GT. A theory of reservation-dwelling American Indian alcohol use risk. Psychol Bull. 2007;133(3):395-418.

17. Walls M. Hartson, KS, Whitbeck LB. North American Indigenous adolescent substance use. Addict Behav 2013;38(5):2103-9.

18. Barrett AE, Turner RJ. Family structure and substance use problems in adolescence and early adulthood: examining explanations for the relationship. Addiction. 2006;101(1):109-20. 
19. Siegel S, Castellan HJ. Estatística não paramétrica para ciências do comportamento. 2 ed. Porto Alegre: Artmed; 2006.

20. Terwee CB, et al. Quality criteria were proposed for measurement properties of health status questionnaires. Journal of Clinical Epidemiology. New York. 2007;60:34-42.

21. Conover WJ. Practical Nonparametric Statistics. New York: John Wiley \& Sons; 1980.

22. Johnson RA. Applied Multivariate Statistical Analysis. New Jersey: Prentice Hall Inc.; 1988.

23. Hair JF, Anderson RE, Tatham RL, Black WC. Análise multivariada de dados. Porto Alegre: Artmed; 2005.

24. Everitt BS. The Analysis of Contingency Tables. London: Chapman and Hall; 1989. 128 p.

25. Johnson R, Bhattacharyya G. Statistics Principles and Methods. New York: John Wiley \& Sons; 1986.

26. Cicchetti DV, Sparrow SA. Developing criteria for establishing interrater reliability of specific items: applications to assessment of adaptive behavior. Am J Ment Defic. 1981;86(2):127-37.

27. Fernandes JA. Selvagens Bebedeiras: Álcool, embriaguez e contatos culturais no Brasil Colonial. [tese]. Niterói: Universidade Federal Fluminense; 2004.

28. Ferreira LO. O "fazer antropológico" em ações voltadas para a redução do uso abusivo de bebidas alcoólicas entre os Mbyá-Guarani, no Rio Grande do Sul. In: Langdon EJ, Garnelo L. (organizadores) Saúde dos Povos Indígenas: Reflexões sobre antropologia participativa. Rio de Janeiro: Editora Contra Capa. 2004.

29. Souza MLP, Garnelo L. Quando, como e o que se bebe: o processo de alcoolização entre populações indígenas do alto Rio Negro, Brasil. Cad Saúde Pública. 2007;23(7):1640-8.

30. Langdon EJM. $O$ abuso de álcool entre os povos indígenas no Brasil: uma avaliação comparativa. In: Souza MLP. Processos de alcoolização indígena no Brasil: perspectivas plurais. Rio de Janeiro: Editora Fiocruz; 2013.

31. Souza JA, Oliveira M, Kohatsu M. O uso de bebidas alcoólicas nas sociedades indígenas: algumas reflexões sobre os Kaingang da bacia do rio Tibagi. Paraná. In: Coimbra, C; Santos, R e Escobar; A.L. (Orgs) Epidemiologia e Saúde dos Povos Indígenas do Brasil. Rio de Janeiro: Editora Fiocruz. 149167. 2003.

32. Oliveira RC, Silva RV, Vargas AMD, Nascimento SS, Mendonça AVM, Ferreira EF. Ugmu ãte kax ãmix kax muk yog hãm agtux kakxoppu puyi yumug amai kax muk xoop - Estamos escrevendo sobre o uso da cachaça para as crianças saberem que não é bom beber. Brasília: Universidade de Brasília, Núcleo de Estudos de Saúde Pública; 2016.

33. Oliveira RC, Silva RV, Vargas AMD, Nascimento SS, Mendonça AVM, Ferreira EF. Ugmu ãte kax ãmix kax muk yog hãm agtux kakxoppu puyi yumug amai kax muk xoop - Estamos escrevendo sobre os problemas da cachaça para as crianças saberem que não é bom beber. Brasília. Universidade de Brasília, Núcleo de Estudos de Saúde Pública; 2016.

34. Donovan JE. Estimated blood alcohol concentrations for child and adolescent drinking and their implications for screening instruments. Pediatrics. 2009;123((6):):975-81. 
35. Cheadle JE, Whitbeck LB. Alcohol use trajectories and problem drinking over the course of adolescence: A study of North American Indigneous youth and their caratakers. J Health Soc Behav. 2011;55((2):):228-45.

36. Whitesell NR, Beals J, Crow CB, Mitchell CM, Novins DK. Epidemiology and etiology of substance use among American Indians and Alsaka Natives: Risks, protection, and implications for prevention. Am J Drug Alcohol Use. 2012;38(5):376-82.

37. Martinez MJ. Ayres SL, Kulls S, Brown E. The relationship between peer, parent, and grandparent norms and intentions to use substances for urnan American Indian. J Child Adolesc Subst Abuse. 2015;24(4):220-7.

38. Rubinger MM, Amorim MS, Marcato AS, \& organizadores. Índios Maxakali: resistência ou morte. Belo Horizonte: Interlivros. 1980.

39. Eitle TM, Johnson-Jennings M, Eitle D. Family structure and adolescent alcohol use problems: Extending popular explanations to American Indiansc. Soc Sci Res. 2013;42(6):146-79.

40. Kunitiz SJ. Life-course observations of alcohol use among Navajo Indians: Natural history or careers? Medical Anthropology Quartely. 2006;20(3):279-96.

41. Pereira PPS, Ott AMT. O processo de alcoolização entre os Tenharim das aldeias do rio Marmelos, AM, Brasil. Interface Comunicação Saúde Educação. 2012;16(43):957-66.

42. Prussing E, Gone JP. Alcohol treatment in Native North America: gender in cultural context. Alcoholism Treatment Quartely. 2011;29:379-402.

\section{Tables}

Table 1

Comparative analysis of the clusters with respect to alcohol consumption.

\begin{tabular}{|c|c|c|c|c|c|}
\hline \multirow[t]{2}{*}{ Alcohol Consumption } & \multicolumn{4}{|c|}{ Clusters } & \multirow[t]{2}{*}{$\mathrm{P}$} \\
\hline & 1 & 2 & 3 & 4 & \\
\hline No & $16(10.3 \%)$ & $151(51.9 \%)$ & $281(100.0 \%)$ & $119(70.8 \%)$ & $<0.001^{*}$ \\
\hline Yes & 140 (89.7\%) & $140(48.1 \%)$ & $\begin{array}{c}0 \\
(0.0 \%)\end{array}$ & $49(29.2 \%)$ & \\
\hline
\end{tabular}

Note: the probability of significance refers to the Chi-square test.

\section{Table 2}

Comparative analysis between clusters in relation to the variables of interest. 


\begin{tabular}{|c|c|c|c|c|c|}
\hline \multirow[t]{2}{*}{ Variables } & \multicolumn{4}{|c|}{ Clusters } & \multirow[t]{2}{*}{$P$} \\
\hline & 1 & 2 & 3 & 4 & \\
\hline \multicolumn{6}{|l|}{ Gender } \\
\hline \multirow[t]{2}{*}{ Male } & & 154 & & & $<$ \\
\hline & $106(67.9 \%)$ & $(52.9 \%)$ & $97(34.5 \%)$ & $81(48.2 \%)$ & $0.001^{*}$ \\
\hline \multirow[t]{2}{*}{ Female } & & 137 & 184 & & \\
\hline & $50(32.1 \%)$ & $(47.1 \%)$ & $(65.5 \%)$ & $87(51.8 \%)$ & \\
\hline \multicolumn{6}{|l|}{ Age group } \\
\hline \multirow[t]{2}{*}{9 to 14 years old } & 0 & 121 & 170 & 0 & $<$ \\
\hline & $(0.0 \%)$ & $(41.6 \%)$ & $(60.5 \%)$ & $(0.0 \%)$ & $0.001^{*}$ \\
\hline \multirow[t]{2}{*}{15 to 19 years old } & 0 & 0 & 0 & 168 & \\
\hline & $(0.0 \%)$ & $(0.0 \%)$ & $(0.0 \%)$ & $(100.0 \%)$ & \\
\hline \multirow{2}{*}{20 to 24 years old } & 0 & & 1 & 0 & \\
\hline & $(0.0 \%)$ & $85(29.2 \%)$ & $(0.4 \%)$ & $(0.0 \%)$ & \\
\hline \multirow[t]{2}{*}{25 to 45 years old } & 156 & 0 & & 0 & \\
\hline & (100.0\%) & $(0.0 \%)$ & $96(34.2 \%)$ & $(0.0 \%)$ & \\
\hline \multirow[t]{2}{*}{46 years or more } & 0 & & 14 & 0 & \\
\hline & $(0.0 \%)$ & $85(29.2 \%)$ & $(5.0 \%)$ & $(0.0 \%)$ & \\
\hline \multicolumn{6}{|l|}{ Family Structure } \\
\hline \multirow[t]{2}{*}{ Nuclear family } & & 52 & 177 & & $<$ \\
\hline & $65(41.7 \%)$ & $(17.9 \%)$ & $(63.0 \%)$ & 57 (33.9\%) & $0.001^{*}$ \\
\hline \multirow[t]{2}{*}{ Single parent family } & 2 & 9 & 13 & 8 & \\
\hline & $(1.3 \%)$ & $(3.1 \%)$ & $(4.6 \%)$ & $(4.8 \%)$ & \\
\hline \multirow[t]{2}{*}{ Extended family } & & 230 & & & \\
\hline & $89(57.1 \%)$ & $(79.0 \%)$ & $91(32.4 \%)$ & $103(61.3 \%)$ & \\
\hline \multicolumn{6}{|l|}{ Use of alcohol by the mother } \\
\hline \multirow[t]{2}{*}{ Yes } & & 234 & 6 & & $<$ \\
\hline & $95(60.9 \%)$ & $(80.4 \%)$ & $(2.1 \%)$ & $70(41.7 \%)$ & $0.001^{*}$ \\
\hline \multirow[t]{2}{*}{ No } & & & 275 & & \\
\hline & $61(39.1 \%)$ & $57(19.6 \%)$ & $(97.9 \%)$ & $98(58.3 \%)$ & \\
\hline \multicolumn{6}{|l|}{ Use of alcohol by the father } \\
\hline \multirow[t]{2}{*}{ Yes } & & 277 & 221 & & $<$ \\
\hline & $155(99.4 \%)$ & $(95.2 \%)$ & $(78.6 \%)$ & 151 (89.9\%) & $0.001^{*}$ \\
\hline \multirow[t]{2}{*}{ No } & 1 & 14 & & & \\
\hline & $(0.6 \%)$ & $(4.8 \%)$ & $60(21.4 \%)$ & $17(10.1 \%)$ & \\
\hline \multicolumn{6}{|c|}{$\begin{array}{l}\text { Monthly per capita household income } \\
\text { (median) }\end{array}$} \\
\hline \multirow[t]{2}{*}{$>\mathrm{R} \$ 65.20$} & & 151 & 137 & & 0.833 \\
\hline & $76(48.7 \%)$ & $(51.9 \%)$ & $(48.8 \%)$ & $81(48.2 \%)$ & \\
\hline \multirow[t]{2}{*}{$\leq \mathrm{R} \$ 65.20$} & & 140 & 144 & & \\
\hline & $80(51.3 \%)$ & $(48.1 \%)$ & $(51.2 \%)$ & $87(51.8 \%)$ & \\
\hline
\end{tabular}

Table 3

Distribution of individuals in the groups formed in the cluster analysis for the determining variable Problems Related to Alcohol Use (PRAU). 


\begin{tabular}{|c|c|c|c|c|}
\hline Cluster & $\begin{array}{l}\text { Determining } \\
\text { variables }\end{array}$ & Characteristics & $\overline{\mathbf{N}}$ & $\%$ \\
\hline$\underline{\text { PRAU1 }}$ & $\begin{array}{l}\text { Don't drink / DNP: } \\
61.6 \% \\
\text { DWP }(\underline{1}): 29.6 \% \\
\underline{\text { DWP }(\underline{1}): 8.8 \%}\end{array}$ & $\begin{array}{l}\text { Gender: Female }(\underline{50.8 \%) ;} ; \\
\text { Age: } 25 \text { to } 45 \text { years }(100 \%) ; \\
\text { Family structure: } \\
\text { Extended family_(50.4\%); } \\
\text { Nuclear family_(48.4\%); } \\
\text { Use of Alcohol by the Mother }(38.8 \%) ; \\
\text { Use of Alcohol by the Father }(89.2 \%) ;\end{array}$ & 250 & 27.9 \\
\hline $\begin{array}{c}\text { C- } \\
\text { PRAU2 }\end{array}$ & $\begin{array}{l}\text { Don't drink / DNP: } \\
94.5 \% \\
\text { DWP (1): } 3.6 \% \\
\text { DWP (+1): } 1.9 \%\end{array}$ & $\begin{array}{l}\text { Gender: Female }(53.4 \%) \text {; } \\
\text { Age: } 9 \text { to } 14 \text { years }(50.5 \%) ; 15 \text { to } 19 \text { years } \\
\text { (36.2\%) } \\
\text { Family structure: } \\
\text { Nuclear Family }(72.2 \%) \\
\text { Use of Alcohol by the Mother }(21.7 \%) \text {; } \\
\text { Use of Alcohol by the Father }(80.3 \%) ;\end{array}$ & 309 & 34.5 \\
\hline $\begin{array}{c}\text { C- } \\
\text { PRAU3 }\end{array}$ & $\begin{array}{l}\text { Don't drink / DNP: } \\
76.3 \% \\
\text { DWP (1): } 21.9 \% \\
\text { DWP (+1): } 1.8 \%\end{array}$ & $\begin{array}{l}\text { Gender: Male ( } 50.7 \%) \text {; } \\
\text { Age: } 9 \text { to } 14 \text { years }(40 \%) ; 15 \text { to } 19 \text { years } \\
\text { (16.6\%); } 20 \text { to } 24 \text { years }(21.1 \%) ; 46 \text { and }+ \\
\text { (22.3\%). } \\
\text { Family structure: } \\
\text { Extended family }(97.9 \%) \text {; } \\
\text { Use of Alcohol by the Mother }(71.5 \%) \text {; } \\
\text { Use of Alcohol by the Father }(98.8 \%) \text {. }\end{array}$ & 337 & 37.6 \\
\hline Total & & & 896 & 100.0 \\
\hline
\end{tabular}

Note: DNP: drink no problem; DWP: drink with problem.

\section{Table 4}

Characterization of the community in relation to the clusters. 


\begin{tabular}{|c|c|c|c|c|c|}
\hline \multirow[t]{2}{*}{ Variables } & \multicolumn{4}{|c|}{ Clusters } & \multirow[t]{2}{*}{$\mathrm{P}$} \\
\hline & 1 & 2 & 3 & 4 & \\
\hline \multicolumn{6}{|l|}{ Community } \\
\hline Pradinho & $91(19.1 \%)$ & $163(34.2 \%)$ & $129(27.0 \%)$ & $94(19.7 \%)$ & 0.028 \\
\hline Água Boa & $65(15.5 \%)$ & $128(30.5 \%)$ & $152(36.3 \%)$ & $74(17.7 \%)$ & \\
\hline \multicolumn{6}{|l|}{ Village } \\
\hline Amantchui & $\begin{array}{c}5 \\
(12.8 \%)\end{array}$ & $\begin{array}{c}9 \\
(23.1 \%) \\
25\end{array}$ & $17(43.6 \%)$ & $\begin{array}{c}8 \\
(20.5 \%)\end{array}$ & प \\
\hline Badé & $15(15.6 \%)$ & $(26.0 \%)$ & $41(42.7 \%)$ & $15(15.6 \%)$ & \\
\hline Cachoeira & $\begin{array}{c}19(22.1 \%) \\
6\end{array}$ & $29(33.7 \%)$ & 17 (19.8\%) & $\begin{array}{c}21(24.4 \%) \\
9\end{array}$ & \\
\hline Gilmar & $\begin{array}{c}(13.6 \%) \\
4\end{array}$ & $\begin{array}{c}13(29.5 \%) \\
5\end{array}$ & $16(36.4 \%)$ & $\begin{array}{c}(20.5 \%) \\
6\end{array}$ & \\
\hline Iara & $\begin{array}{c}(14.8 \%) \\
0\end{array}$ & $\begin{array}{c}(18.5 \%) \\
3\end{array}$ & $\begin{array}{c}12(44.4 \%) \\
2\end{array}$ & $\begin{array}{c}(22.2 \%) \\
1\end{array}$ & \\
\hline Joviel & $\begin{array}{c}(0.0 \%) \\
7\end{array}$ & $(50.0 \%)$ & $(33.3 \%)$ & $\begin{array}{c}(16.7 \%) \\
5\end{array}$ & \\
\hline Kokiti & $\begin{array}{c}(19.4 \%) \\
3\end{array}$ & $11(30.6 \%)$ & $\begin{array}{c}13(36.1 \%) \\
6\end{array}$ & $\begin{array}{c}(13.9 \%) \\
3\end{array}$ & \\
\hline Major & $(13.6 \%)$ & $\begin{array}{c}10(45.5 \%) \\
65\end{array}$ & $(27.3 \%)$ & $(13.6 \%)$ & \\
\hline Maravilha & $\begin{array}{c}25(19.2 \%) \\
4\end{array}$ & $\begin{array}{c}(50.0 \%) \\
7\end{array}$ & $\begin{array}{c}20(15.4 \%) \\
0\end{array}$ & $\begin{array}{c}20(15.4 \%) \\
4\end{array}$ & \\
\hline Marcelo & $\begin{array}{c}(26.7 \%) \\
3\end{array}$ & $(46.7 \%)$ & $\begin{array}{c}(0.0 \%) \\
0\end{array}$ & $\begin{array}{c}(26.7 \%) \\
2\end{array}$ & \\
\hline Mariazinha & $(20.0 \%)$ & $10(66.7 \%)$ & $(0.0 \%)$ & $(13.3 \%)$ & \\
\hline Nova & $14(18.4 \%)$ & $23(30.3 \%)$ & 25 (32.9\%) & $14(18.4 \%)$ & \\
\hline Nova Raízes & $\begin{array}{c}4 \\
(16.0 \%)\end{array}$ & $\begin{array}{c}5 \\
(20.0 \%)\end{array}$ & $\begin{array}{c}13 \\
(52.0 \%) \\
9\end{array}$ & $\begin{array}{c}3 \\
(12.0 \%)\end{array}$ & \\
\hline Novila & $\begin{array}{c}16(23.9 \%) \\
2\end{array}$ & $\begin{array}{c}24(35.8 \%) \\
2\end{array}$ & $(13.4 \%)$ & $\begin{array}{c}18(26.9 \%) \\
3\end{array}$ & \\
\hline Tomé & $\begin{array}{c}(11.8 \%) \\
1\end{array}$ & $\begin{array}{c}(11.8 \%) \\
3\end{array}$ & $\begin{array}{c}10(58.8 \%) \\
0\end{array}$ & $\begin{array}{c}(17.6 \%) \\
3\end{array}$ & \\
\hline Valdemar & $\begin{array}{c}(14.3 \%) \\
12\end{array}$ & $(42.9 \%)$ & $(0.0 \%)$ & $(42.9 \%)$ & \\
\hline Vila Nova & $\begin{array}{c}(13.0 \%) \\
5\end{array}$ & $\begin{array}{c}17(18.5 \%) \\
5\end{array}$ & $48(52.2 \%)$ & $\begin{array}{c}15(16.3 \%) \\
6\end{array}$ & \\
\hline Vila Vila & $(19.2 \%)$ & $(19.2 \%)$ & $10(38.5 \%)$ & $(23.1 \%)$ & \\
\hline Zé Pirão & $11(15.7 \%)$ & $25(35.7 \%)$ & $22(31.4 \%)$ & $12(17.1 \%)$ & \\
\hline House of religion & & & & & \\
\hline No house of religion & $75(17.6 \%)$ & $162(38.1 \%)$ & $115(27.1 \%)$ & $73(17.2 \%)$ & 0.003 \\
\hline With house of religion & $81(17.2 \%)$ & $129(27.4 \%)$ & $166(35.2 \%)$ & $95(20.2 \%)$ & \\
\hline
\end{tabular}




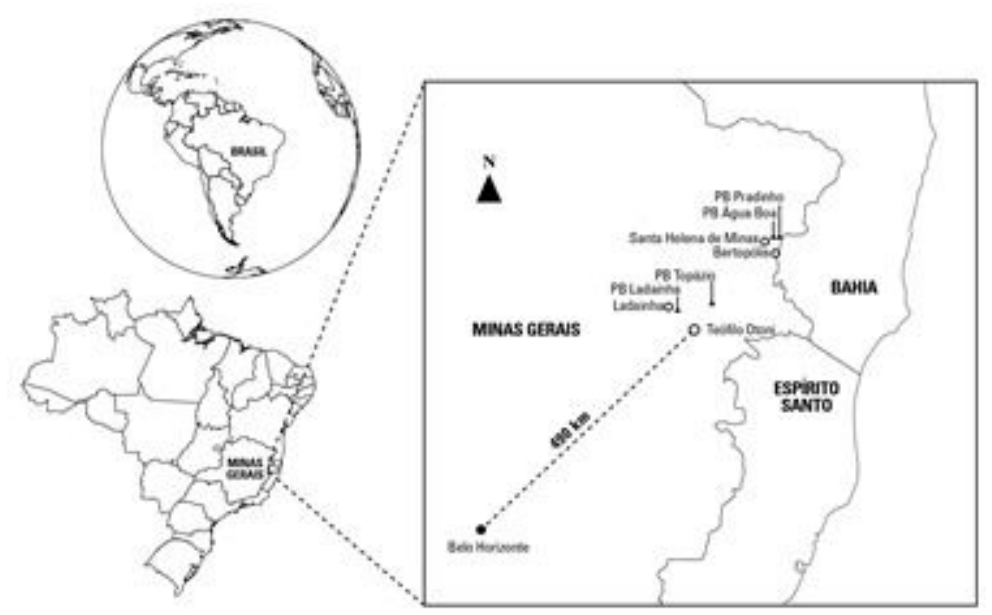

\section{Figure 1}

Map of the Brazilian territory highlighting the study site.

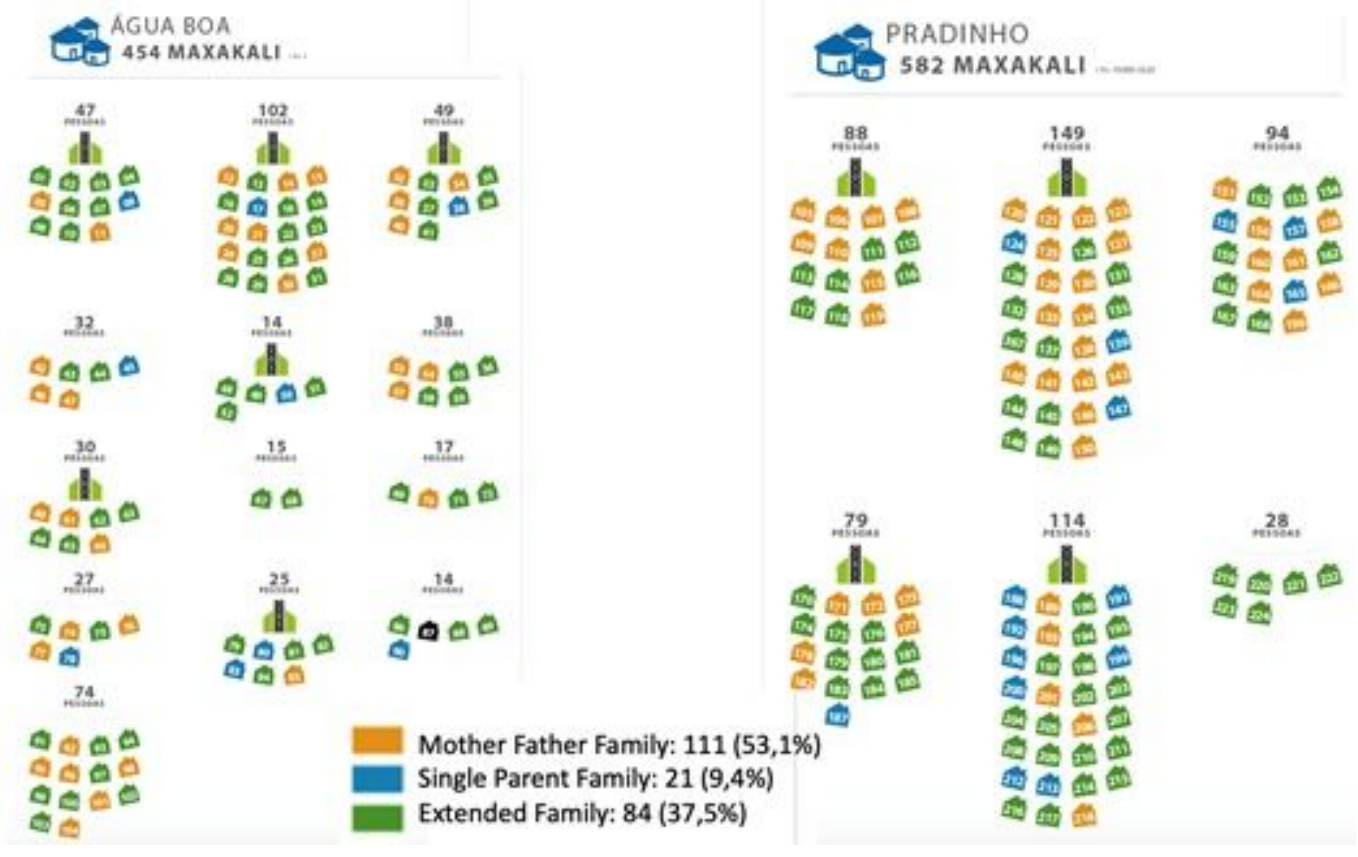

\section{Figure 2}

Scheme of the type of family constitution and number of individuals living in the studied villages. 